\title{
Methylphenidate and Alprazolam Co-Abuse: Drug-DNA Interactions
}

\section{Meenu Dutt ${ }^{1}$, Neha Sharma ${ }^{1}$, Ravinder Naik Dharavath ${ }^{2}$, Tanzeer Kaur ${ }^{3}$, and Shweta Sharma $^{1^{*}}$}

1 Institute of Forensic Sciences and Criminology, Panjab University, Chandigarh-160014

2 Pharmacology Research Laboratory, University Institute of Pharmaceutical Sciences, Panjab University, Chandigarh-160014 India.

3 Department of Biophysics, Panjab University, Chandigarh-160014

\section{Corresponding author}

Dr. Shweta Sharma, Institute of Forensic Sciences and Criminology, Panjab University, Chandigarh-160014, India. Mobile: +919827688577; Email: 25shweta@pu.ac.in and 25shweta@gmail.com

\begin{abstract}
Drug abuse is a major issue worldwide. Methylphenidate (MPH) and alprazolam (ALZ) are commonly prescribed drugs for the treatment of ADHD and anxiety disorders, respectively. The limited studies suggest that abusers primarily use benzodiazepines to counteract adverse effects associated with methylphenidate usage. The main aim of this study was to investigate the interaction of drugs with DNA using spectroscopic methods. Female Wistar rats were administered with MPH $(10,20,40 \mathrm{mg} / \mathrm{kg})$ and $\operatorname{ALZ}(5,10,20 \mathrm{mg} / \mathrm{kg})$ alone and in combination for a period of 28 days. The FT-IR and UV results reveal some spectral changes in a dose-dependent manner, which indicates interactions of drugs with DNA. Thus, the changes in spectral peaks provide some insight into the mechanism of the interaction of drugs with DNA.
\end{abstract}

Keywords: Drug-DNA interaction, FTIR, Polydrug-abuse, UV-visible spectrophotometer. 


\section{INTRODUCTION}

Polydrug use is a major trend of drug use, especially among young people these days. Methylphenidate (MPH) is a short-acting central nervous system (CNS) stimulant drug prescribed for the treatment of various neurobehavioral disorders, including ADHD (Attention deficit hyperactivity disorder) and narcolepsy (Leonard et al. 2004). CNS stimulants are also known as "neuroenhancers or smart pills," which help users improve their ability to perform better. Anxiety, hyperactivity, sleep disorders, delusions, aggression, and irritability are the most prevalent adverse effects of these medications (Waldman et al. 2011).

Alprazolam (ALZ) is a highly potent anti-anxiety medication widely prescribed to treat panic attacks, anxiety disorders, and anxiety mixed depression (Verster and Volkerts 2004). In contrast to other benzodiazepines (BZD), ALZ is considered safe; however, its extended use has several adverse effects, including addiction and substance dependency (Isbister et al. 2004). In order to combat these adverse effects, CNS depressants are taken along with stimulants or as self-medication (non-prescription), which are known to slow down the functioning of the brain's motor activity and produce relaxing, sedative and tranquilizing effects (Babcock, 2017). There are some cases reported where the abusers administer ALZ, assuming that it could subside the side effects of MPH (Paolo Busardò et al. 2016; Dimitrova et al. 2017). We have reported the results for hepato and neuro toxicity with the same dose on co-administration of ALZ and MPH (Dutt et al. 2020a, b). This study focus on investigating the spectrophotometric interaction of DNA with drugs. Moreover, earlier in vitro studies have established that alprazolam intercalates with the DNA (Saha et al. 2009). DNA (Deoxyribonucleic acid) is a vital genetic molecule that constitutes most of the genetic information and aids the biological synthesis of proteins and enzymes through essential processes like replication and transcription (Travers and Muskhelishvili 2015). Drug DNA interaction studies are valuable for screening new and more efficient drugs targeting DNA, investigating the structure and biological function of DNA, and elucidating the damage mechanism of DNA.

In contrast, in the case of MPH, studies have been reported noncovalent intercalation with DNA (Snyder et al. 2006). The present study aimed at the examination and evaluation of drug- DNA interactions in a dose-dependent manner in rats. The work involves in vivo studies to understand the effect of chronic treatment with ALZ and MPH, both individually and in combination with the DNA of rats by using UV-visible spectrophotometer and FTIR techniques.

\section{MATERIALS AND METHODS}

\section{Drugs and kits}

ALZ and MPH were procured as marketed formulations manufactured by Malladi Drugs and Pharmaceuticals Ltd. (Chennai, India) and IPCA Pharmaceuticals (Mumbai, India), respectively. Only analytical grade chemicals and reagents were used in this study. DNA isolation kit was purchased from Qiagen DNase Blood and Tissue kit (Cat No. /ID: 69504, U.S.A.)

\section{Animals}

Six to eight-week-old female Wistar rats $(200-250 \mathrm{~g})$ were acquired from the Central animal house facility of Panjab University and were housed $(n=3$ animal per cage) in standard laboratory animal housing environment (temperature: $25 \pm 2{ }^{\circ} \mathrm{C}$; relative humidity: $45-55 \%$ ) with 12:12h light: dark cycle and ad libitum access to food (Ashirwad Industries Chandigarh, India) and water. The Institutional Animal Ethics Committee 
(PU/45/99/CPCSEA/IAEC/2018/126) of the Panjab University approved the use of animals, and all studies were carried out in compliance with the guidelines agreed by the committee for control and supervision of experiments on animals (CPCSEA), Government of India.

\section{Experimental Design}

Female Wistar rats $(n=30)$ were randomly divided into ten different groups. Briefly, a normal control (NC; $n=3$ ), and three groups (low dose-LD; mid dose-MD; high dose- HD) of each drug treatment. The alprazolam treated groups (ALZ; 5, $10 \& 20 \mathrm{mg} / \mathrm{kg}$ p.o.; $\mathrm{n}=3$ each dose) and Methylphenidate (MPH; 10, $20 \& 40 \mathrm{mg} / \mathrm{kg}$ p.o.; $\mathrm{n}=3$ each dose). Whereas, the remaining three groups were administered with a combination of ALZ and MPH (A+M; $5+10 \mathrm{mg} / \mathrm{kg} ; 10+20$ $\mathrm{mg} / \mathrm{kg}$ and $20+40 \mathrm{mg} / \mathrm{kg}$ p.o.; $\mathrm{n}=3$ each dose). A $20 \mu \mathrm{L}$ of Tween-20 (Polysorbate-20) was added to the powdered tablets and suspended in $15 \mathrm{ml}$ of distilled water. Every day fresh suspensions were prepared before their oral administration for 28 days.

\section{Drug-DNA interaction studies}

\section{Euthanasia and DNA Extraction}

DNA was extracted from the liver tissue of rat using Qiagen DNeasy Blood and Tissue kit (Cat No: 69504) by following the standard protocol of the kit. The extracted DNA samples were stored at $-20^{\circ} \mathrm{C}$ for further instrumental analysis.

\section{UV spectroscopic method}

UV-Visible spectroscopy is a simple and most frequently used analytical method for examination of drug- DNA interactions. This evaluation was done by tracking the variations in the absorption characteristics of the drug and DNA molecules and is usually done by examining the deviation in the wavelength of the maximum absorption of the drug-exposed to the animal DNA compared to the maximum of normal DNA (Leonova et al. 2017). The UV-Visible absorption spectrum of DNA shows broadband (200-350 nm) in the UV region with maximum absorption at $260 \mathrm{~nm}$. The UV spectra of liver DNA samples from drug-treated animals were recorded with a Shimadzu dual-beam UV-visible spectrophotometer UV- 2550 using a $1 \mathrm{~cm} \times$ $1 \mathrm{~cm}$ quartz cuvettes. The UV-visible spectra of DNA samples were recorded in the wavelength range of $200-350 \mathrm{~nm}$.

\section{FTIR spectroscopy}

FT-IR spectroscopy is a powerful method and is often used to study and characterize drugDNA interactions. It dominates revealing structural details of the whole molecule in the target sample and can offer evidence related to the specific binding site of small molecules on the nucleic acid. The fingerprint region for DNA structural study is confined in the spectral region of $1800-600 \mathrm{~cm}^{-1}$. This region is of popular attention because ring vibrations of nitrogenous bases $(\mathrm{C}=\mathrm{O}, \mathrm{C}=\mathrm{N}$ stretching), phosphate stretching vibrations (symmetric and asymmetric), and deoxyribose stretching of DNA backbone are confined to this region (Jangir et al. 2011; Sirajuddin et al. 2013). Perkin Elmer Fourier analyzed the characteristics peaks of DNA transformed Infrared (FTIR) spectrophotometer equipped with ATR having diamond crystal and $\mathrm{ZnSe}$ as a focusing element. The spectra of samples were collected in the spectral range of $4000-600 \mathrm{~cm}^{-1}$ with a resolution of $8 \mathrm{~cm}^{-1}$. Background spectra of blank ATR crystal and with elution buffer were collected before each measurement. 


\section{Results}

\section{UV-visible spectroscopy}

The spectroscopic result of UV-vis shows a hypochromic shift in all three drug-treated groups, as shown in fig 1 and Table 1 shows the maximum absorbance of all treated groups.

A

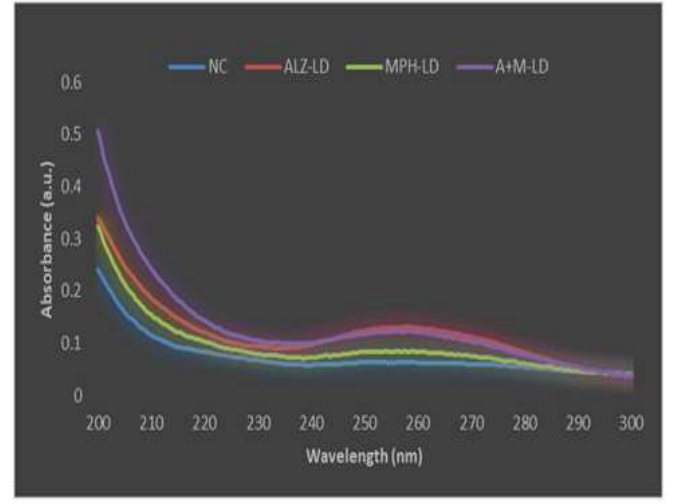

C

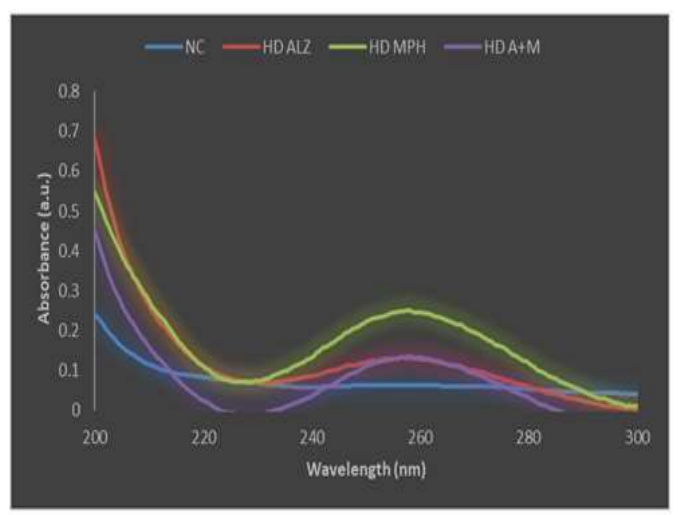

B

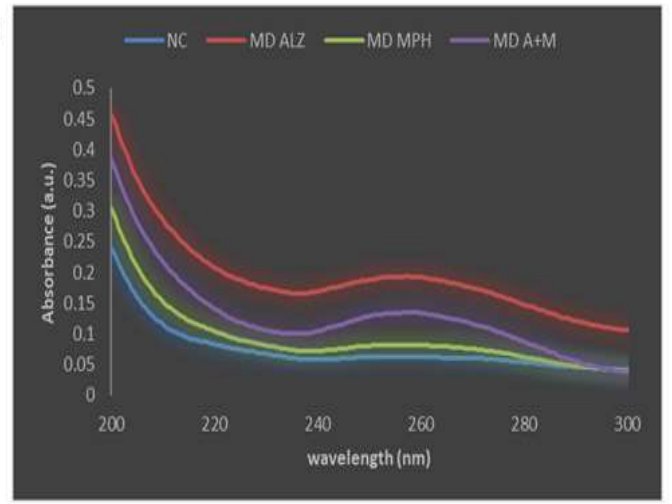

D

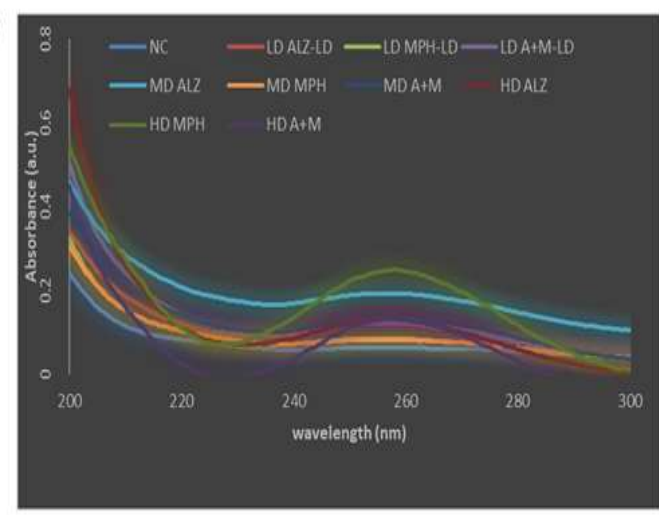

Fig 1. UV-Visible spectra of DNA normal control (NC), ALZ treated DNA, MPH treated DNA, and combination of ALZ and MPH $(\mathrm{A}+\mathrm{M})$ treated DNA at a low dose (A), mid-dose (B), high dose(C) stacked view of all doses (D).

Table 1. Absorbance of all the treated groups normal control (NC), alprazolam (ALZ), methylphenidate (MPH), ALZ+MPH $(\mathrm{A}+\mathrm{M})$

\begin{tabular}{|l|c|c|c|c|}
\hline Dose & $\begin{array}{l}\lambda \text { max of DNA } \\
(\mathbf{n m}) \mathbf{N C}\end{array}$ & $\begin{array}{l}\boldsymbol{\lambda} \text { max of DNA } \\
(\mathbf{n m}) \text { in ALZ }\end{array}$ & $\begin{array}{l}\lambda \mathbf{m a x} \text { of DNA } \\
(\mathbf{n m}) \text { in MPH }\end{array}$ & $\begin{array}{l}\lambda \mathbf{m a x} \text { of DNA } \\
(\mathbf{n m}) \text { in A+M }\end{array}$ \\
\hline Low dose & 260 & 258.4 & 257.6 & 257.4 \\
\hline Mid Dose & 260 & 258.7 & 257.8 & 258.5 \\
\hline High Dose & 260 & 257.5 & 258.5 & 257.5 \\
\hline
\end{tabular}

\section{FTIR Spectroscopy}

Animals treated with a low dose of ALZ (5mg/kg/day), MPH (10mg/kg/day), and combination of these $(5 \mathrm{mg} / \mathrm{kg} / \mathrm{day}$ ALZ \& $10 \mathrm{mg} / \mathrm{kg} \mathrm{MPH})$ exhibit no marked changes were observed in FTIR spectra of DNA when compared to DNA of NC. In a medium dose of ALZ $(10 \mathrm{mg} / \mathrm{kg}$ 
/day), MPH (20mg/kg /day), and combination of A+M exhibit, minor shifting of peaks in FTIR spectra of DNA compared to NC.

On treatment with high dose of ALZ, a shift in peak from 1719 (Guanine) $\mathrm{cm}^{-1}$ to $1718 \mathrm{~cm}^{-1}$, $1484 \mathrm{~cm}^{-1}$ (Cytosine) to $1474 \mathrm{~cm}^{-1}, 1224 \mathrm{~cm}^{-1}$ (phosphate symmetric vibrations ) to $1226 \mathrm{~cm}^{-1}$, $1084 \mathrm{~cm}^{-1}$ ( phosphate asymmetric vibrations) to $1085 \mathrm{~cm}^{-1}, 1043$ (ring vibrations) $\mathrm{cm}^{-1}$ to 1045 $\mathrm{cm}^{-1}$ and 877 (sugar-phosphate stretch) $\mathrm{cm}^{-1}$ to $878 \mathrm{~cm}^{-1}$.

MPH presents peak shift from 1719 (Guanine) $\mathrm{cm}^{-1}$ to $1720 \mathrm{~cm}^{-1}, 1484 \mathrm{~cm}^{-1}$ (Cytosine) to 1487 $\mathrm{cm}^{-1}, 1224 \mathrm{~cm}^{-1}$ (phosphate symmetric vibrations ) to $1230 \mathrm{~cm}^{-1}, 1084 \mathrm{~cm}^{-1}$ (phosphate asymmetric vibrations) to $1085 \mathrm{~cm}^{-1}, 1043$ (ring vibrations) $\mathrm{cm}^{-1}$ to $1045 \mathrm{~cm}^{-1}, 877 \mathrm{~cm}^{-1}$ (sugarphosphate stretch) $\mathrm{cm}^{-1}$ to $879 \mathrm{~cm}^{-1}$ and $837 \mathrm{~cm}^{-1}$ ( phosphodiester mode ) to $841 \mathrm{~cm}^{-1}$.

On combination of these drugs $(\mathrm{A}+\mathrm{M})$ peak shifts from $1484 \mathrm{~cm}^{-1}$ (Cytosine) to $1474 \mathrm{~cm}^{-1}$, $1224 \mathrm{~cm}^{-1}$ (phosphate symmetric vibrations ) to $1228 \mathrm{~cm}^{-1}, 1084 \mathrm{~cm}^{-1}$ (phosphate asymmetric vibrations) to $1083 \mathrm{~cm}^{-1}, 1043$ (ring vibrations) $\mathrm{cm}^{-1}$ to $1045 \mathrm{~cm}^{-1}$ and 877 (sugar-phosphate stretch) $\mathrm{cm}^{-1}$ to $879 \mathrm{~cm}^{-1}$. Animals treated with ALZ in higher dose shows peak shift from 1719 (Guanine) $\mathrm{cm}^{-1}$ to $1717 \mathrm{~cm}^{-1}, 1484 \mathrm{~cm}^{-1}$ (Cytosine) to $1483 \mathrm{~cm}^{-1}, 1224 \mathrm{~cm}^{-1}$ (phosphate symmetric vibrations ) to $1229 \mathrm{~cm}^{-1}, 1084 \mathrm{~cm}^{-1}$ ( phosphate asymmetric vibrations) to 1080 $\mathrm{cm}^{-1}, 1043$ (ring vibrations) $\mathrm{cm}^{-1}$ to $1045 \mathrm{~cm}^{-1}$ and 837 (phosphodiester mode) $\mathrm{cm}^{-1}$ to $840 \mathrm{~cm}^{1}$. The FT-IR spectra of all the groups are shown in fig 2 and the change in wavenumber is shown in table 2.

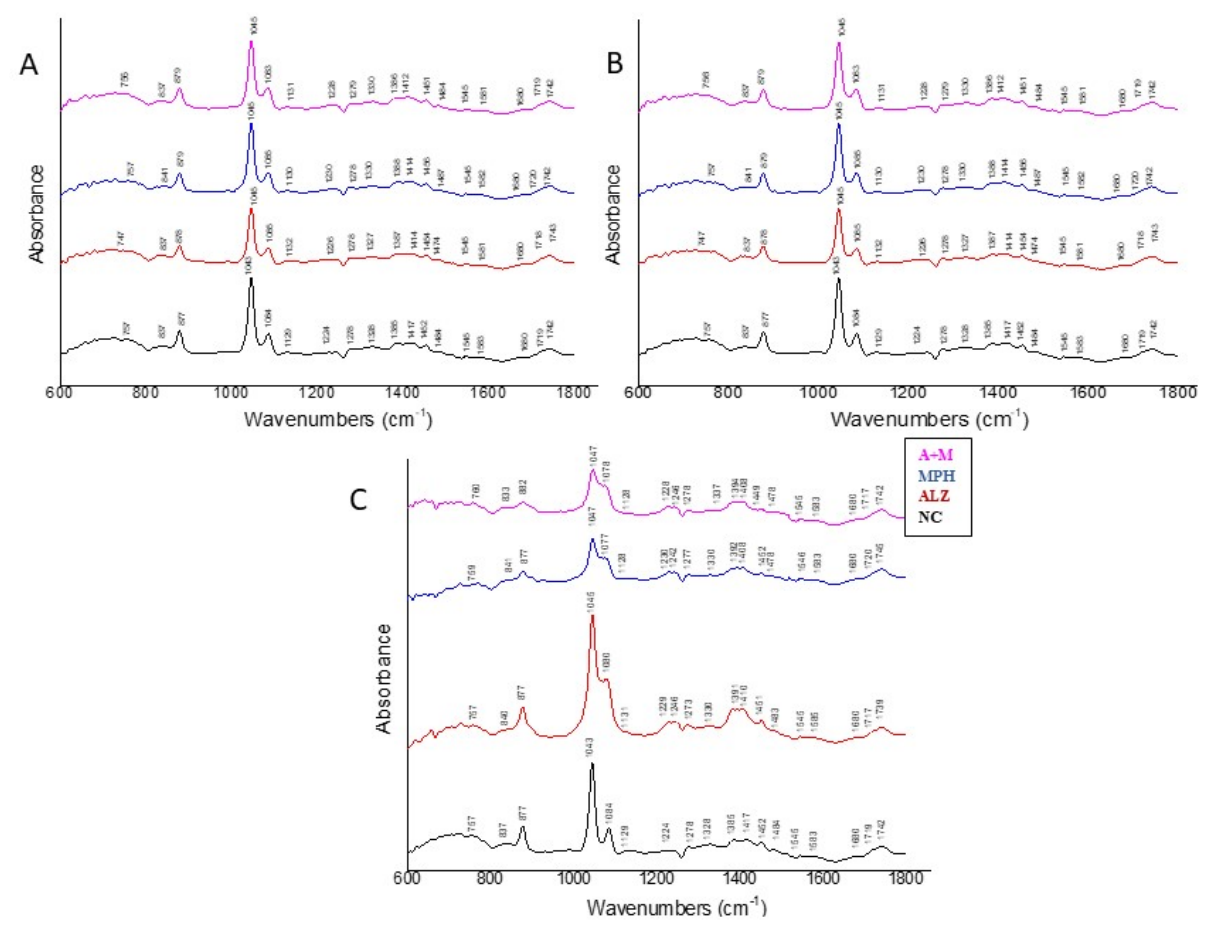

Fig 2. Stacked view of FTIR spectra of DNA normal control (NC), ALZ treated DNA, MPH treated DNA, and combination of ALZ and MPH $(\mathrm{A}+\mathrm{M})$ treated DNA at low doses(A), middose(B), high dose(C). 
Table 2. Shift in bindings of DNA via FT-IR; Normal control (NC), ALZ treated DNA, MPH treated DNA, and combination of ALZ and MPH $(\mathrm{A}+\mathrm{M})$ treated DNA at mid and high doses. G (guanine), C (cytosine), P.S.V (phosphate symmetric vibrations), R.V (ring vibration), P.A.V(phosphate asymmetric vibrations), S.B.S (sugar-phosphate stretch), P.M (phosphodiester mode).

\begin{tabular}{|l|l|l|l|l|l|l|l|l|}
\hline & \multirow{2}{*}{$\begin{array}{l}\text { Possible } \\
\text { Bindings }\end{array}$} & \multirow{2}{*}{ NC } & \multicolumn{2}{l|}{ ALZ } & \multicolumn{2}{l|}{ MPH } & \multicolumn{2}{l|}{ A+M } \\
\cline { 3 - 8 } & & & MD & HD & MD & HD & MD & HD \\
\hline 1 & G & $1719 \mathrm{~cm}^{-1}$ & 1718 & 1717 & 1720 & 1720 & 1719 & 1717 \\
\hline 2 & C & $1484 \mathrm{~cm}^{-1}$ & 1474 & 1483 & 1487 & 1478 & 1474 & 1478 \\
\hline 3 & P.S.V & $1224 \mathrm{~cm}^{-1}$ & 1226 & 1229 & 1230 & 1230 & 1228 & 1228 \\
\hline 4 & P.A.V & $1084 \mathrm{~cm}^{-1}$ & 1085 & 1080 & 1085 & 1077 & 1083 & 1083 \\
\hline 5 & R.V & $1043 \mathrm{~cm}^{-1}$ & 1043 & 1045 & 1045 & 1047 & 1045 & 1047 \\
\hline 6 & S.P.S & $877 \mathrm{~cm}^{-1}$ & 878 & 879 & 879 & 879 & 879 & 882 \\
\hline 7 & P.M & $837 \mathrm{~cm}^{-1}$ & 838 & 840 & 840 & 841 & 837 & 841 \\
\hline
\end{tabular}

\section{Discussion}

Several studies have documented the concurrent abuse of stimulants (cocaine, methamphetamine) with depressants (heroin, morphine). The co-administration of stimulants and depressants has shown to cause enhanced rewarding effect depicting the increased popularity of these combination drugs among abusers. The spectral change in drug-treated groups of various prominent structural positions (nitrogen bases and bonds) of DNA is evidence for the interaction (Maziak et al. 2007).

Compounds binding with DNA through intercalation mode usually results in hypsochromism (blue shift) and bathochromic (redshift). The degree of hypochromism is usually proportional to the strength of interaction as an interaction includes stacking between the drug and the base pair of DNA (Dorraji and Jalali 2013). On treatment with ALZ, MPH, and A+M at all three

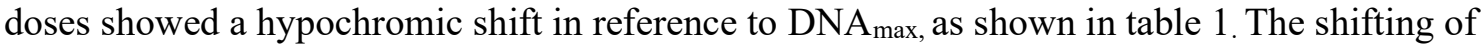
absorption attributes to the intercalation between DNA base pairs (DNA induced hypochromism). This intercalation strength is directly proportional to the concentration of the drug (Jangir et al. 2010; Sirajuddin et al. 2013). In a B-to-A transition, B DNA marker bands at $837 \mathrm{~cm}^{-1}$ due to phosphodiester mode and at $1719 \mathrm{~cm}^{-1}$ due to Guanine shift toward lower frequencies, also, the band at $1224 \mathrm{~cm}^{-1}$ due to symmetric phosphate vibrations shifts towards higher frequencies about $1230-1240 \mathrm{~cm}^{-1}$ (Saito et al. 2012). When a B to $\mathrm{Z}$ transition takes place, the band at $837 \mathrm{~cm}^{-1}$ displaces to $800 \mathrm{~cm}^{-1}$, and the band at $1719 \mathrm{~cm}^{-1}$ appears near 1690 $\mathrm{cm}^{-1}$, whereas the band at $1224 \mathrm{~cm}^{-1}$ shifts toward $1215 \mathrm{~cm}^{-1}$ (Alex and Dupuis 1989).

The findings of drug-DNA interactions in our study, based on the previous reports (Saha et al. 2009), we found the DNA intercalating properties of ALZ, and MPH might play a crucial role in toxicity enhancement. The shifting of absorption maxima from $260 \mathrm{~nm}$ to lower wavelengths in animals treated with ALZ and MPH at low, medium and high doses attributes to the intercalation of ALZ, MPH, and combination $(\mathrm{A}+\mathrm{M})$ between DNA base pairs. This intercalation strength is directly proportional to the concentration of the intercalating agent (drug). The extent of shifting of absorption maximum is greater in high dose samples revealing the risk of administration of higher doses of these drugs individually and in combination (Saha et al. 2009; Jangir et al. 2011). The maximum absorption shift is obtained due to the presence of chromophoric groups in purine (adenine and guanine) and pyrimidine (cytosine and 
thymine) moieties, which are directly responsible for the electronic transitions (Hajian and Guan Huat 2013).

The fingerprint region for DNA structural study is confined in the spectral region of 1800-600 $\mathrm{cm}^{-1}$. This region is of popular attention because ring vibrations of nitrogenous bases $(\mathrm{C}=\mathrm{O}$, $\mathrm{C}=\mathrm{N}$ stretching), phosphate stretching vibrations (symmetric and asymmetric), and deoxyribose stretching of DNA backbone are confined to this region. The peak shifts are attributed to the drug-DNA complexation and indicate drug intercalation into DNA duplex, which results in the alteration of nucleobase vibrational frequencies. Shifting in peaks of phosphate symmetric and asymmetric vibrations indicates some weak exterior interaction of ALZ, MPH, and combination $(\mathrm{A}+\mathrm{M})$ with the DNA double helix. The minor variations observed in the peaks at $1719 \mathrm{~cm}^{-1}$ and $1224 \mathrm{~cm}^{-1}$ are not symbolic of DNA conformational change and confirm that DNA remains in B state of confirmation (Reddy et al. 1999; Cai et al. 2009; Saha et al. 2009)

\section{Conclusion}

UV and FTIR data suggest some intercalative properties with not many conformational changes. Besides, the wide absorption bands produced by several vibrational peaks, these changes in spectral peaks provide some insight into the mechanism of the interaction of drugs with DNA, as shown in fig 3. Spectroscopic studies have a limitation in identifying molecular interactions, so it can be chosen as a future perspective.

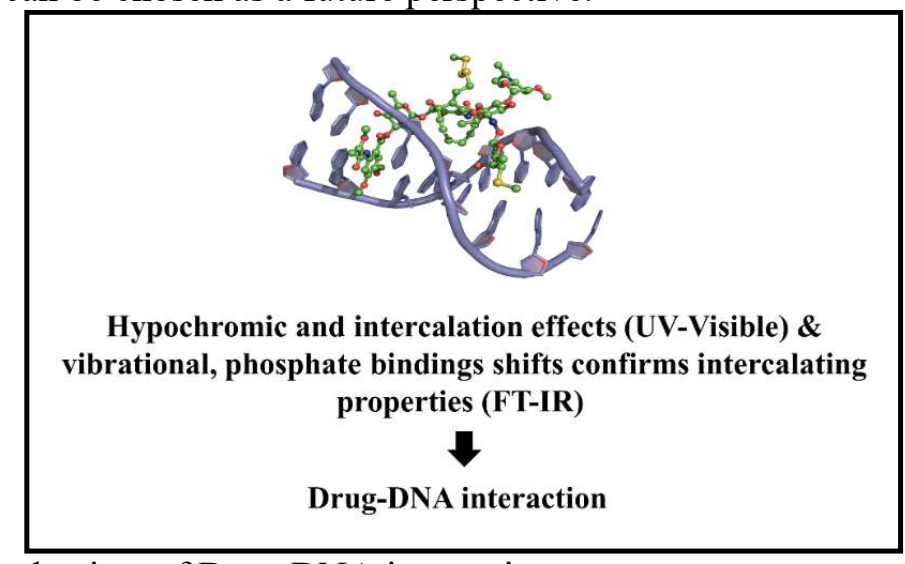

Fig 3. Possible mechanism of Drug-DNA interaction

Acknowledgments: The authors duly acknowledge the University Grants Commission, New Delhi, India, for providing fellowship to Ms. Meenu Dutt.

Conflicts of Interest: Authors declare no conflicts of interest

\section{References}

Alex S, Dupuis P (1989) FT-IR and Raman investigation of cadmium binding by DNA. Inorganica Chim Acta 157:271-281. https://doi.org/10.1016/S0020-1693(00)80552-6

Cai X, Gray PJ, Von Hoff DD (2009) DNA minor groove binders: Back in the groove. Cancer Treat Rev 35:437-50. https://doi.org/10.1016/j.ctrv.2009.02.004

Dimitrova N, Zamudio JR, Jong RM, et al (2017) Public Access NIH Public Access. PLoS One 32:736-740. https://doi.org/10.1371/journal.pone.0178059

Dorraji PS, Jalali F (2013) Investigation of the interaction of sertraline with calf thymus DNA by spectroscopic methods. J Braz Chem Soc 24:939-945. https://doi.org/10.5935/0103- 
5053.20130123

Dutt M, Dharavath RN, Kaur T, et al (2020a) Differential effects of alprazolam against methylphenidate-induced neurobehavioral alterations. Physiol Behav 222:1-12. https://doi.org/10.1016/j.physbeh.2020.112935

Dutt M, Dharavath RN, Kaur T, et al (2020b) Co-abuse of alprazolam augments the hepatorenal toxic effects of methylphenidate. Indian $\mathrm{J}$ Pharmacol 52:. https://doi.org/10.4103/ijp.IJP_758_19

Hajian R, Guan Huat T (2013) Spectrophotometric studies on the thermodynamics of the DSDNA interaction with irinotecan for a better understanding of anticancer drug-DNA interactions. J Spectrosc 2013:1-8. https://doi.org/10.1155/2013/380352

Isbister GK, O’Regan L, Sibbritt D, Whyte IM (2004) Alprazolam is relatively more toxic than other benzodiazepines in overdose. $\mathrm{Br} \mathrm{J}$ Clin Pharmacol 58:88-95. https://doi.org/10.1111/j.1365-2125.2004.02089.x

Jangir DK, Charak S, Mehrotra R, Kundu S (2011) FTIR and circular dichroism spectroscopic study of interaction of 5-fluorouracil with DNA. J Photochem Photobiol B Biol 105:143148. https://doi.org/10.1016/j.jphotobiol.2011.08.003

Jangir DK, Tyagi G, Mehrotra R, Kundu S (2010) Carboplatin interaction with calf-thymus DNA: A FTIR spectroscopic approach. J Mol Struct 1:126-129. https://doi.org/10.1016/j.molstruc.2010.01.052

Leonard BE, McCartan D, White J, King DJ (2004) Methylphenidate: A review of its neuropharmacological, neuropsychological and adverse clinical effects. Hum Psychopharmacol 19:151-180. https://doi.org/10.1002/hup.579

Leonova E, Shvirksts K, Grube M, et al (2017) Spectrophotometric study of DNA interactions with ftorafur and its elementoorganic derivatives. Toxicol Environ Chem 99:610-13. https://doi.org/10.1080/02772248.2016.1273614

Maziak DE, Do MT, Shamji FM, et al (2007) Fourier-transform infrared spectroscopic study of characteristic molecular structure in cancer cells of esophagus: An exploratory study. Cancer Detect Prev 31:244-253. https://doi.org/10.1016/j.cdp.2007.03.003

Paolo Busardò F, Kyriakou C, Cipolloni L, et al (2016) From Clinical Application to Cognitive Enhancement: The Example of Methylphenidate. Curr Neuropharmacol 14:17-27. https://doi.org/10.2174/1570159x13666150407225902

Reddy BSP, Sondhi SM, Lown JW (1999) Synthetic DNA minor groove-binding drugs. Pharmacol Ther 84:1-111. https://doi.org/10.1016/S0163-7258(99)00021-2

Saha B, Mukherjee A, Santra CR, et al (2009) Alprazolam intercalates into DNA. J Biomol Struct Dyn 26:421-429. https://doi.org/10.1080/07391102.2009.10507257

Saito ST, Silva G, Pungartnik C, Brendel M (2012) Study of DNA-emodin interaction by FTIR and UV-vis spectroscopy. J Photochem Photobiol B Biol 111:59-63. https://doi.org/10.1016/j.jphotobiol.2012.03.012

Sirajuddin M, Ali S, Badshah A (2013) Drug-DNA interactions and their study by UV-Visible, fluorescence spectroscopies and cyclic voltametry. J Photochem Photobiol B Biol 124:119. https://doi.org/10.1016/j.jphotobiol.2013.03.013

Snyder RD, Ewing D, Hendry LB (2006) DNA intercalative potential of marketed drugs testing positive in in vitro cytogenetics assays. Mutat Res - Genet Toxicol Environ Mutagen 609:47-59. https://doi.org/10.1016/j.mrgentox.2006.06.001

Travers A, Muskhelishvili G (2015) DNA structure and function. FEBS J.

Verster JC, Volkerts ER (2004) Clinical Pharmacology, Clinical Efficacy, and Behavioral Toxicity of Alprazolam: A Review of the Literature. CNS Drug Rev 10:45-76. https://doi.org/10.1111/j.1527-3458.2004.tb00003.x

Waldman ID, Ph D, Charney E, et al (2011) Dose Effects and Comparative Effectiveness. J Child Adolesc Psychopharmacol 21:581-588. https://doi.org/10.1089/cap.2011.0018 